\title{
Jornadas de Otoño 2007: ¿Un paso más hacia un consenso nacional sobre alteraciones respiratorias del sueño?
}

Las $26^{\circ}$ Jornadas de Otoño de la Sociedad Chilena de Enfermedades Respiratorias estuvieron dedicadas a los Trastornos Respiratorios del Sueño en adultos y niños. Se debe destacar el interés de los especialistas por asistir a esta instancia de discusión y de actualización de conocimientos en este tema, lo cual estimamos se debe a la importancia creciente de la apnea de sueño en la práctica de la clínica neumológica.

En el programa dedicado a neumólogos de adultos, el objetivo de las jornadas fue revisar tanto aspectos básicos como clínicos de la apnea de sueño, para lo cual nuestra Sociedad invitó al Dr. Atul Malhotra, profesor y jefe del programa de Trastornos del Sueño de la Universidad de Harvard. También contamos con la destacada participación de distinguidos miembros de la Sociedad y de connotados invitados nacionales de otras especialidades.

En primer lugar se revisaron los avances en la patogenia de la apnea obstructiva, destacando las hipótesis que explican la diferencia de respuesta de los seres humanos frente a una oclusión de la vía aérea superior. A continuación se realizó un panel sobre aspectos diagnósticos, clínicos y de laboratorio de sueño. Se reafirmó la importancia de la sospecha clínica siendo síntomas ejes los ronquidos y la hipersomnia diurna.

¿A quién estudiar? fue una de las preguntas planteadas y que tiene relación con los factores de riesgo para desarrollar Apnea Obstructiva y con sus consecuencias cardiovasculares. La forma de estudiar un paciente con sospecha clínica también fue detalladamente comentada, en particular las diferentes alternativas de evalución en el hospital y ámbito ambulatorio.

El Dr. Malhotra desarrolló ulteriormente el tema de las apneas centrales y la respiración de Cheyne-Stokes que complica especialmente a pacientes con insuficiencia cardiaca avanzada. En otra de sus charlas, el especialista de la Universidad de Harvard, presentó la última evidencia sobre la relación causal entre la apnea obstructiva del sueño y morbi-mortalidad cardiovascular.

En el $2^{\circ}$ día de las jornadas se realizó un panel con los aspectos terapéuticos de la Apnea Obstructiva del sueño. En primer lugar se enfatizaron las medidas médicas del manejo, especialmente lo relacionado con la obesidad, sin duda principal factor en la presentación de este síndrome. A continuación se hizo una exposición sobre las diferentes formas de aplicación de la presión positiva de la vía aérea, tratamiento de elección de esta patología. También se revisó el aspecto quirúrgico desarrollado por el Dr. Enrique Hanuch, invitado otorrinolaringólogo, de la Clínica Alemana.

Junto con agradecer el esfuerzo desplegado por todos quienes hicieron posible estas jornadas en el ámbito de la neumología de adultos, esperamos que la información obtenida por los especialistas nacionales beneficie significativamente a nuestros pacientes.

¿Quién se habría imaginado hace 10 años que un grupo significativo de neumólogos pediatras, se reuniría en un centro de convenciones, durante un día y medio, para actualizar los conocimientos e intercambiar su experiencia en alteraciones respiratorias del sueño (ARS) en el niño? Esto habla de la relevancia que está alcanzando este tema, tradicionalmente subvalorado, en la práctica pediátrica.

En el programa pediátrico de las jornadas de otoño destacó el excelente nivel de los invitados nacionales y particularmente de la profesora invitada extranjera, Dra. Carole Marcus, Jefe del Laboratorio de Sueño del Children's Hospital of Philadelphia, referente obligado de la subespecialidad por su importante contribución a la estandarización de la polisomnografía y valores de referencia, $e$ investigación fisiopatológica que han aportado significativamente a la comprensión y manejo de las 
ARS. Ella nos transmitió con generosidad y sencillez sus conocimientos en estas áreas y su experiencia en grupos específicos de patologías: malformaciones cráneo-faciales, espina bífida, enfermedades neuromusculares, síndrome de Down y síndromes de hipoventilación central. Su brillante conferencia plenaria "Relación entre apnea obstructiva del sueño del niño y del adulto" despertó un vivo interés en neumólogos pediatras y neumólogos de adultos, dejando en claro las diferencias fisiopatológicas y clínicas entre ambos grupos de pacientes y algunos aspectos compartidos en la historia natural de esa condición patológica. Por otra parte los pediatras también disfrutaron con la excelente conferencia plenaria "Patogenia de la apnea obstructiva del sueño" del Dr. Atul Malhotra profesor invitado extranjero en el programa neumológico de adultos de estas jornadas.

Otros temas analizados en las $26^{\circ}$ Jornadas de Otoño fueron: la saturometría nocturna, con una interesante discusión acerca de su estandarización y valores de referencia; la experiencia del Centro de Sueño de Clínica Alemana en el Síndrome de Apnea Obstructiva del Sueño en la edad pediátrica en general y en grupos específicos como pacientes con malformaciones cráneo-faciales, con enfermedades neuromusculares y con malformación de Chiari. Además se analizó el efecto deletéreo del tabaquismo materno en el sueño del niño, al disminuir las respuestas de despertar y aumentar los indices de eventos respiratorios, especialmente obstructivos y en sueño activo, conociendo de paso las propiedades del receptor neuronal nicotínico de acetilcolina.

También revisamos el síndrome de resistencia aumentada de vía aérea como parte del espectro clínico de las ARS obstructivas. Se analizó su frecuente subdiagnóstico, el impacto negativo en el área cognitiva y neuropsicológica y la promisoria técnica de medición del tiempo de tránsito de pulso, como un marcador sensible del trabajo respiratorio aumentado en esta condición, sin necesidad del método más invasivo de medición de presión intraesofágica. Además, pudimos contrastar la visión de un neurólogo y de un broncopulmonar al momento de evaluar y manejar pacientes con patología neuromuscular y enriquecernos de la experiencia de un centro nacional, el Centro de Enfermedades Respiratorias Infantiles (CEDERI), en ventilación mecánica invasiva y no invasiva en pacientes crónicos.

Finalmente no podemos dejar de destacar la conferencia histórico-cultural a cargo del neurofisiólogo Dr. Ennio Vivaldi V., profesor de la Facultad de Medicina, Universidad de Chile, quien nos invitó a un viaje cultural fascinante, a través de la ciencia y de la historia, con un fino sentido del humor, mientras nos preguntábamos: ¿Por qué soñamos?

Nuestro sincero agradecimiento a todos quienes contribuyeron al éxito de esta actividad. Creemos que estas jornadas representan un paso más hacia el desarrollo de un consenso nacional y el objetivo de ver a esta disciplina convertida en una subespecialidad.

\author{
Dr. Selim Abara E. \\ Coordinador, Programa Pediátrico
}

Dr. Fernando Descalzi M. Coordinador, Programa Neumológico Adultos 